\title{
Emergências de saúde pública: breve histórico, conceitos e aplicações
}

\author{
Public health emergencies: brief history, concepts, and applications
}

Eduardo Hage Carmo'

DOI: 10.1590/0103-11042020E201

\section{Introdução}

Os processos históricos de mudanças nos padrões de morbidade e mortalidade no mundo, a partir da segunda metade do século passado, têm sido denominados de transição epidemiológica. Essa denominação, estabelecida por Omran', visou estabelecer o que estaria relacionado, no campo da saúde, com outros processos de mudanças nos padrões populacionais, definido como transição demográfica ${ }^{2}$. De forma resumida, a redução na taxa de fecundidade das populações, a redução na mortalidade infantil e o aumento da expectativa de vida ao nascer, que se observava principalmente nos países desenvolvidos (mas que seria seguido, após um lapso de tempo e de forma uniforme, pelos países menos desenvolvidos), estariam associados à redução na mortalidade por doenças transmissíveis, com maior impacto em crianças. Esse grupo de doenças estava sendo superado pelas doenças crônico-degenerativas, mais frequentes em grupos etários mais avançados. Às três etapas do processo de transição epidemiológica descritas inicialmente, que ocorreriam de acordo com o estágio de desenvolvimento do País, incorporou-se uma quarta etapa, caracterizada pela redução de algumas doenças crônicas, em especial, das doenças cardiovasculares ${ }^{3}$. Como modelo explicativo para esses processos, destacava-se a disponibilidade e o uso das tecnologias médicas (especialmente antibióticos e vacinas), o que justificaria a redução das doenças transmissíveis, mais facilmente controláveis - em princípio - a essas tecnologias.

Entretanto, essa concepção não explicaria as mudanças mais recentes que se observavam em países menos desenvolvidos (em especial na América Latina e no Caribe), como discutido por alguns autores ${ }^{4}$, que evidenciavam diferentes padrões de comportamento das tendências epidemiológicas desses países. A redução das doenças transmissíveis nessas nações foi relativa, coexistindo ainda em elevados níveis com a elevada carga de doenças crônicas não transmissíveis. A partir dessas evidências, considerou-se que esses países teriam um processo de transição incompleta.

Barreto et al. ${ }^{5}$ também observaram que as mudanças nos padrões epidemiológicos não são lineares, ou seja, ocorrem de forma diferente para cada país e em cada grupo populacional,

1 Fundação Oswaldo Cruz (Fiocruz) - Brasília (DF), Brasil.

ehcarmo@gmail.com em função das condições específicas de vida de cada um desses grupos. Utilizando-se como referência outras análises dessas mudanças globais ${ }^{6}$, os autores identificaram que os fatores determinantes da melhoria de alguns indicadores epidemiológicos não estariam restritos ao 
ao uso de tecnologias médicas, embora esses tivessem alguma influência, mas estariam relacionados com as melhorias nas condições de vida das populações. O impacto das tecnologias em saúde (não somente as tecnologias médicas) estaria também condicionado pelo acesso das populações não apenas a essas tecnologias, mas também a sua própria condição de vida. Dessa forma, o conceito de transição (ou seja, passagem de um estágio mais desenvolvido a outro) não se sustentaria, assim como a sua justificação.

Essa concepção está alinhada às análises sobre as mudanças nas condições de vida das populações abordadas a partir das perspectivas dos determinantes sociais da saúde e das desigualdades sociais ${ }^{7}$. Segundo essa perspectiva, a persistência, ou mesmo o aprofundamento dessas desigualdades, representam uma barreira para a melhoria das condições de saúde das populações.

Assim, o entendimento das mudanças nos padrões epidemiológicos deve ser abordado de uma forma mais abrangente. Mais além da então denominada transição epidemiológica, o cenário recente é caracterizado pela ocorrência de múltipla carga de doenças e agravos (transmissíveis, não transmissíveis, violência, transtornos mentais), com a coexistência de diversos grupos de doenças, com maior ou menor expressão de cada um desses grupos, de acordo com os estratos populacionais considerados ${ }^{8}$.

No que diz respeito às doenças transmissíveis, a permanência de fatores (entre eles, a manutenção ou o aprofundamento das desigualdades) que determinam ou condicionam a produção e disseminação dessas doenças em níveis elevados, as alterações nos padrões de transmissão e de circulação de pessoas, bens e mercadorias, que favorecem o aumento a velocidade da disseminação das doenças infecciosas, propiciam as condições para o surgimento de epidemias, de novas doenças, assim como o recrudescimento de antigas doenças.

Também no campo das doenças e agravos não transmissíveis, tem havido um aumento na exposição aos riscos relativos aos padrões de consumo (por exemplo, tabagismo, alimentação não saudável, sedentarismo, uso de álcool e drogas, entre outros), às condições de trabalho adversas, ao uso de agrotóxicos e outras exposições a produtos químicos e aos riscos associados ao uso de tecnologias de saúde.

Associado a esses fatores, a relação do homem com a natureza - determinado pelos processos de produção, consumo, ocupação do espaço e manejo da terra, geradores de degradação ambiental, favorecendo as mudanças climáticas - tem amplificado o risco de ocorrência de desastres e potencializado seus efeitos sobre a saúde das populações, especialmente as mais vulneráveis.

\section{Principais emergências de saúde pública no presente século}

Se considerarmos o presente século como limite temporal para uma breve análise, podemos identificar uma série de eventos agudos de saúde, que evidenciam a elevada frequência e gravidade com que incidem na população e a diversidade de agentes e fatores envolvidos na sua produção e disseminação ou propagação. Para o propósito desta breve descrição, estão incluídas, não de forma exaustiva, emergências de saúde pública de diferentes naturezas e origens, abarcando epidemias, doenças emergentes e desastres.

O ano de 2001 foi marcado pela ocorrência de dois eventos intencionais nos Estados Unidos, embora de natureza e características bastante diversas. $\mathrm{O}$ primeiro deles, $\mathrm{o}$ ataque terrorista por meio do uso da aviação civil ao World Trade Center (WTC) e a outros locais do País ocorrido em setembro daquele ano, provocou a morte imediata de aproximadamente 3 mil pessoas, a maioria delas presentes no WTC, bem como 490 mil pessoas afetadas por diversos problemas de saúde relacionados direta ou indiretamente com o evento. $\mathrm{O}$ ataque evidenciou uma série de fragilidades 
na capacidade de resposta a eventos dessa natureza e magnitude no País, mas contribuiu para o fortalecimento nacional e global dessas capacidades ao longo dos anos ${ }^{9-11}$.

O País ainda não havia se recuperado daquele ataque, quando, em outubro do mesmo ano, teve início a propagação intencional de esporos do Bacillus anthracis, por meio de envelopes postais, gerando 22 casos (5 óbitos) de Antraz em diversos estados ${ }^{12}$. Esse, que foi posteriormente considerado um ato bioterrorista 'endógeno' 13 , provocou ainda um colapso no serviço postal, nos serviços de atenção à saúde e nos laboratórios.

Já no ano seguinte, uma epidemia provocada por uma doença então desconhecida teve início em novembro de 2002 na província de Guangdong - China, disseminou-se para outros territórios desse país e, posteriormente, para outros continentes, caracterizando uma pandemia. A doença apresentava um quadro clínico de pneumonia atípica, com evolução mais grave que a usualmente registrada para outras etiologias virais, sendo denominada de Síndrome Respiratória Aguda Grave (Sars em inglês). Tendo como agente etiológico um novo coronavirus ${ }^{\mathbf{1 4}}$, produziu 8.098 casos $(774$ óbitos) em 26 países. A partir de alguns episódios de transmissão que ocorreram no hotel Metrópole de Hong Kong, em fevereiro de $2003^{15}$, deu-se a disseminação internacional para outros continentes por meio de viagens aéreas, evidenciando como se poderia produzir uma pandemia em um período de pouco mais de 24 horas. Uma outra característica importante dessa pandemia foi a amplificação da transmissão em ambiente hospitalar (e outros serviços de saúde), o que tornou os profissionais de saúde alvos da doença e potenciais transmissores para outros locais.

Em 2004, a ocorrência de casos de influenza humana pelo vírus H5N1 no Vietnam e na Tailândia acendeu o alerta para a possibilidade da ocorrência de uma pandemia por esse vírus, tendo em vista que toda a população mundial estaria susceptível à infecção. Esses casos estavam associados a uma epizootia ocorrida em aves no final de 2003, em oito países da Ásia, o que indicava a transmissão interespécies, embora essa transmissão já viesse sendo detectada desde 1997 em Hong Kong'16. Por se tratar de uma nova cepa de vírus influenza infectando humanos, a possibilidade de que houvesse a transmissão sustentada inter-humanos, a reduzida eficácia dos antivirais utilizados e a gravidade dos casos até então conhecidos (letalidade ao redor de $50 \%$ ) produziram uma série de possíveis paralelos com pandemias anteriormente causadas por vírus influenza, com suas respectivas estimativas de mortes: H1N1 em 1918 (mais de 40 milhões), H2N2 em 1957 (4 milhões) e H3N2 em 1968 (1 milhão).

Já no ano de 2005, um evento de natureza não infecciosa ocorrido nos Estados Unidos provocou imensos danos na população, além de perdas materiais, econômicas (custo estimado de US\$ 108 bilhões) e deslocamentos da população. O furacão Katrina que atingiu Nova Orleans nesse ano teve efeitos devastadores, provocando a morte de mais de 1.500 pessoas, além dos desaparecidos. Em que pesem as lições aprendidas com eventos anteriores, especialmente com o ataque terrorista de 2001, o enfrentamento das consequências desse desastre foi considerado muito insuficiente pelo próprio Congresso Nacional17.

A pandemia de influenza pelo vírus $\mathrm{H} 5 \mathrm{~N} 1$, esperada em anos anteriores, não se concretizou, mas, a partir de fevereiro de 2009 , iniciou-se uma nova pandemia, dessa vez, produzida pelo vírus influenza $\mathrm{A}[\mathrm{H} 1 \mathrm{N1}]$ pdm09. Essa pandemia foi considerada a primeira emergência de saúde pública de importância internacional, já adotando os novos critérios do Regulamento Sanitário Internacional (RSI 2005), que havia entrado em vigor dois anos antes ${ }^{\mathbf{1 8}}$. A pandemia teve início em fevereiro daquele ano, na fronteira do México com os Estados Unidos, sendo que as estimativas iniciais indicavam uma elevada gravidade, as quais foram baseadas em um estudo realizado no México, que evidenciava uma letalidade de $41 \%$ durante o início da pandemia' ${ }^{19}$. Entretanto, essas estimativas não se confirmaram, sendo que as 
projeções posteriores para o número de mortos se situaram entre 123.000 e 395.600 mortos $^{\mathbf{1 8}}$. Não é possível estimar, com uma boa precisão a letalidade por essa pandemia, tendo em vista que o registro do número de casos foi suspenso globalmente, logo ainda no ano de 2009.

O Brasil também foi seriamente afetado pela pandemia, com uma rápida disseminação em poucas semanas após o seu início. Ao final de 2009, 50.482 casos graves e 2.060 óbitos haviam sido confirmados, especialmente na região sul do País. Como o Brasil implementou um sistema de detecção de casos graves, foi possível estimar a letalidade $(4,1 \%)$, a qual se situava na média observada para a influenza sazonal20,21.

Em março de 2011, após ser atingida por um tsunami provocado por um maremoto, a Central Nuclear de Fukushima apresentou o derretimento de três turbinas, liberando quantidades significativas de material radioativo, o que se constituiu o maior desastre nuclear desde $o$ acidente nuclear de Chernobil, ocorrido em $1986^{22}$. O número de pessoas afetadas, ou que ainda podem manifestar doenças relacionadas com o acidente, é pouco preciso, mas estima-se que 18.500 pessoas foram a óbito, com 200 mil sendo atingidos pelo evento"1.

Entre o final de 2013 e o início de 2014, uma epidemia pelo vírus Ebola começou a afetar a República de Guiné, expandindo-se rapidamente para Libéria e Serra Leoa (África Ocidental) e produzindo um total de 28.616 casos com 11.310 mortes $^{\mathbf{2 3 , 2 4}}$, o que corresponderia a uma letalidade de $39,5 \%$. Entretanto, esse percentual provavelmente foi subestimado, considerando a letalidade média registrada em epidemias anteriores e a precariedade dos serviços de saúde nos países envolvidos ${ }^{25}$. Essa epidemia também foi considerada pela Organização Mundial da Saúde (OMS) uma emergência de saúde pública de importância internacional, segundo os critérios do RSI 2005, e durou dois anos, sendo finalizada em 29 de março de $2016^{24}$.

Nesse mesmo período, duas epidemias estavam se disseminando no continente americano, ambas transmitidas pelo mesmo vetor, o Aedes aegypti: a febre do Chikungunya e a infecção pelo vírus Zika, com suas graves consequências. Essas epidemias afetaram seriamente o Brasil a partir de 2014, especialmente após a detecção do aumento de síndromes neurológicas (no caso de Chikungunya e de Zika) e das alterações congênitas associadas à infecção materna pelo vírus Zika no final de 201526,27. Com os novos achados referentes às alterações congênitas pelo vírus Zika no Brasil e com a disseminação para outros países, decorridos quatro meses após a declaração de emergência no País, a OMS declarou emergência de saúde pública de importância internacional ${ }^{\mathbf{2 8}}$.

Embora epidemias pelo vírus Zika já houvessem sido registradas na África e na Ásia, até então essas manifestações graves da infecção congênita eram desconhecidas. No entanto, após a sua ocorrência no nordeste do Brasil, passou-se a conhecer o amplo espectro de manifestações, que foram encontradas não somente no País, mas em todos os demais continentes, embora em menor intensidade. Desde o início da epidemia até maio de 2019, mais de 3.406 casos do que veio a ser denominado posteriormente de Síndrome Congênita do Zika já foram confirmados ${ }^{29}$. Em muitos países onde houve disseminação da epidemia, não se conhece de forma precisa a magnitude da síndrome, embora a infecção pelo vírus Zika já tenha se disseminado para 87 países, até julho de $2019^{30}$.

Ainda no Brasil, em 2017, ao mesmo tempo que se observava uma redução importante na epidemia pelo vírus Zika, teve início uma nova epidemia de Febre Amarela Silvestre. $\mathrm{O}$ País já havia enfrentado epidemias nas duas décadas anteriores, em menor magnitude, por exemplo, em 1999/2000 (76 e 85 casos respectivamente) e 2008/2009 (46 e 47 casos respectivamente) ${ }^{31}$. Na epidemia que se iniciou no período de monitoramento (forma atual de análise temporal dos casos pelo Ministério da Saúde) de 2016/2017, foram confirmados 768 casos humanos, observando-se grande expansão da área de transmissão dessa virose 
em direção leste e sul do País ${ }^{29}$. Nos períodos subsequentes, houve continuidade na expansão geográfica da epidemia, com o registro de 1.376 (2017/2018) e 88 casos confirmados (2018/2019). Em todos esses últimos períodos, como já vinha sendo registrado desde final do século passado, foram registrados casos em áreas onde não havia registro há mais de 40 anos, indicando uma mudança no padrão geográfico da doença no Brasil ${ }^{\mathbf{3 1}}$.

A partir de meados de 2018, o continente africano novamente foi afetado por uma epidemia pelo vírus Ebola, dessa vez, na República Democrática do Congo. Este país já vinha apresentando periodicamente epidemias em menores proporções, sendo as últimas em 2014 e 2017, devido à situação de vulnerabilidade (guerras, pobreza e fome extrema). Entretanto, a atual epidemia assumiu uma magnitude mais relevante que as anteriores, com o registro de 3.175 casos, entre os quais, 2.122 evoluíram para óbito (letalidade 67\%) até 24 de setembro de $2019^{32}$.

No Brasil, uma epidemia recente vem sendo causada pelo sarampo. Embora, nos últimos anos, tenha havido registro de epidemias localizadas em alguns estados (Pernambuco em 2013/2014 e Ceará em 2014/2015) ${ }^{33}$, a partir de 2018, a disseminação e a magnitude desse evento assumiram proporções bem maiores, levando à perda do certificado de eliminação da doença concedida pela Organização PanAmericana da Saúde (Opas) em 2016. Com a ocorrência da epidemia na região norte do País em 2018, vinculada à epidemia na Venezuela - entre janeiro e setembro de 2019 em todas as regiões, mas predominando em São Paulo (95\% dos casos) ${ }^{33}$-, evidenciou-se que a reintrodução da doença no Brasil encontrava ambiente favorável devido, dentre outros fatores, às baixas coberturas em alguns grupos populacionais, bem como à continua importação de casos procedentes de países que nunca alcançaram a eliminação, especialmente na Europa e na Ásia. Cabe ainda lembrar que a reintrodução da doença nas Américas não ocorreu somente no Brasil e na Venezuela, mas atingiu outros países da região como os
Estados Unidos, que também enfrentaram uma importante epidemia (31 estados afetados) ${ }^{\mathbf{3 4}}$.

Ainda nesse ano, o País foi palco de mais uma tragédia, considerado um dos maiores desastres ambientais, decorrente do rompimento de barragem de rejeitos de mineração da empresa Vale S.A. em Brumadinho (MG). Aproximadamente 300 pessoas morreram ou se encontram desaparecidas (ainda continuam sendo encontrados corpos), 18 municípios e 2 bacias hidrográficas foram diretamente atingidas e os danos ambientais ainda estão sendo mensurados. Esse foi o segundo evento relacionado com a barragem de rejeitos nos últimos anos, tendo em vista que, em 2015, um desastre com características semelhantes ocorreu em Mariana (MG), afetando também o estado do Espírito Santo, envolvendo a empresa Samarco (subsidiária da Vale S.A.), tendo como consequência a morte de 19 pessoas, além dos danos ambientais ${ }^{35}$.

Esses eventos de saúde cada vez mais se expressam de forma abrupta, inusitada, apresentando um alto impacto na população e superando a capacidade de resposta dos serviços de saúde. Visando caracterizar a forma em que esses eventos ocorrem e identificar as medidas mais apropriadas para detecção e resposta, alguns termos têm sido utilizados na literatura internacional e pelos serviços de saúde, o que será discutido a seguir.

\section{Sobre as definições de doenças emergentes e reemergentes}

O surgimento de novas doenças devido à ocorrência de novos agentes etiológicos, cepas ou mecanismos de transmissão, alterações nos agentes já existentes (com aumento na virulência ou patogenicidade) e a introdução de agentes em novas áreas até então consideradas indenes, que são fatores potencialmente geradores de epidemias, além do desenvolvimento de novas técnicas que permitem a 
detecção dessas novas doenças, estimularam a elaboração de conceitos que buscassem caracterizar esses processos e contribuir para a sua detecção, prevenção e controle. Da mesma forma, o ressurgimento de doenças até então consideradas controladas também representaria um risco de produção de epidemias, dado que a população de um determinado território poderia estar susceptível, dependendo do período em que o agente estivesse sem circular ou com reduzida circulação nesse espaço ${ }^{36}$.

Para o primeiro conjunto de eventos, utilizou-se o termo doenças emergentes, enquanto para o segundo, o termo doenças reemergentes. Esses termos surgiram no início da década de 1990, inicialmente utilizados pelo Instituto de Medicina ${ }^{37}$ e, posteriormente, pelo Centers for Disease Prevention and Control dos Estados Unidos (CDC), definiu doenças emergentes como "doenças de origem infecciosa cuja incidência em humanos tem aumentado dentro das últimas duas décadas ou ameaça aumentar no futuro próximo"38(2).

Barreto et al. ${ }^{39}$ identificaram algumas imprecisões no conceito de doenças emergentes, embora seja utilizado amplamente na literatura mundial e adotado por diversos organismos de saúde: a) estabelece um período artificial (duas décadas) para caracterizar uma infecção como emergente; b) não estabelece uma dimensão territorial para que a análise da distribuição de uma doença seja adequadamente contextualizada; c) não estabelece parâmetros para caracterizar um aumento na incidência de uma doença, ou seja, não considera a magnitude desse aumento e a tendência histórica anterior.

Em 2003, o Instituto de Medicina atualizou o documento de 1992, definindo doença emergente como

[...] uma doença infecciosa clinicamente distinta, que tenha sido recentemente reconhecida, ou uma doença infecciosa conhecida cuja incidência esteja aumentando em um dado lugar ou entre uma população específica40(32).
Essa nova definição é mais precisa, na medida em que incorpora a dimensão espacial (ou seja, exige a contextualização territorial) e não estabelece um período artificial, mas, como constataram Barreto et al. ${ }^{39}$, persistia ainda a imprecisão sobre os parâmetros para caracterizar um aumento na incidência de uma doença.

Como ressaltaram Carmo et al. ${ }^{36}$, para uma melhor caracterização de uma doença infecciosa como emergente, é necessária uma análise da ocorrência de forma contextualizada para cada população, território e tempo histórico, nos quais as doenças incidem. Deve ser analisado se o seu surgimento ou o aumento na sua incidência tem relevância epidemiológica para uma população e território definido. Em relação ao tempo a ser considerado na caracterização de uma doença como emergente ou reemergente, cabe a lembrança de Waldman ${ }^{41}$, que destacam a necessidade de que a definição sobre o recorte do comportamento (temporal) de uma doença leve em conta o seu padrão histórico de evolução. Podemos afirmar que não seria possível estabelecer um período único, para todas as doenças, para a caracterização de uma emergência ou reemergência. Essa escolha sempre será arbitrária e adotada para facilitar a descrição de um conjunto de doenças.

\section{Definições de emergências de saúde pública}

Com a aprovação do novo RSI pela Assembleia Mundial da Saúde em 2005, um outro conceito foi difundido, o de emergência de saúde pública ${ }^{\mathbf{4 2}}$.

Entretanto, esse conceito não foi estabelecido inicialmente pelo RSI 2005, mas já estava presente em uma série de publicações, embora quase sempre relacionado com a aplicação de intervenções por organizações nacionais para controlar eventos que poderiam gerar epidemias ou ante epidemias já instaladas. O termo emergência de saúde pública já constava em ato normativo do governo dos Estados Unidos em $1984^{43}$. Seja em atos normativos, seja em algumas publicações, esse termo geralmente é 
utilizado para definir um status de um problema de saúde que exige das autoridades sanitárias a adoção de medidas imediatas para seu controle, em especial, medidas que restringem direitos individuais (por exemplo, quarentena, isolamento, exame compulsório) ou que justifique a mobilização de recursos (humanos, infraestrutura, financeiros). A utilização do termo emergência de saúde pública nesses documentos não traz uma definição, em que são estabelecidos os critérios pelos quais um evento de saúde possa ser classificado como tal ${ }^{44}$.

Inicialmente, a utilização do termo naquele país se aplicava predominantemente para as doenças transmissíveis. Entretanto, com a ocorrência de uso intencional de armas biológicas (liberação de bacilo de Antraz em 2001), com o ataque terrorista de setembro de 2001 e com a ocorrência de desastres de grandes proporções como o furacão Katrina, o termo passou a ser aplicado cada vez mais para caracterização de eventos de outra natureza ${ }^{\mathbf{4 5}, 46}$. Ainda assim, observava-se uma diversidade muito grande no seu uso em instrumentos legais para a definição do termo emergência entre os estados daquele país ${ }^{45}$.

O termo emergência de saúde pública representa um elemento central no RSI 2005, mas deve ser interpretado quanto a sua aplicação para fins desse instrumento. O RSI 2005 tem como objetivo estabelecer medidas para ampliar as capacidades nacionais para detectar e responder aos riscos de disseminação ou propagação (no caso de eventos não infecciosos) de doenças entre os países. Nesse instrumento, o termo utilizado é emergência de saúde pública de importância internacional - definido por:

Evento extraordinário, o qual é determinado, como estabelecido neste regulamento: por constituir um risco de saúde pública para outro Estado por meio da propagação internacional de doenças [e] por potencialmente requerer uma resposta internacional coordenada42(9).

Ainda, segundo as definições do RSI 2005, "Evento significa a manifestação de uma doença ou uma ocorrência que cria um potencial para doença"42(7).

Os eventos que podem se constituir emergências, portanto, não estão restritos às doenças infecciosas (podem incluir eventos de natureza química, radionuclear ou desastres) nem se limitam à ocorrência de dano à saúde da população (caso ou óbito por determinada doença), mas incluem fatores de risco para sua ocorrência.

Para a análise dos eventos que podem se constituir uma emergência de saúde pública de importância internacional, são avaliados alguns critérios de forma contextualizada para uma população, tempo e espaço específicos, além de considerar aspectos relacionados com a probabilidade de restrições internacionais ao trânsito de pessoas, bens e mercadorias e ao comércio internacional. Para essa finalidade, foi desenvolvido um instrumento que conta com instrutivo para sua aplicação e inclui um algoritmo, com algumas perguntas que apoiam a interpretação dos eventos sob análise ${ }^{\mathbf{4 7}}$.

Conforme ressaltaram Carmo et al. ${ }^{36}$, a utilização e a adaptação do conceito de emergência de saúde pública tornaram mais precisa e aplicável pelos sistemas nacionais de vigilância epidemiológica a definição de eventos que deveriam ser objeto de monitoramento, proposição e execução de ações que visassem evitar ou diminuir a probabilidade de disseminação ou propagação de doenças. Ademais, ao tratar de riscos, permite a adoção de medidas antecipatórias, com o potencial de evitar ou reduzir a ocorrência de dano à saúde população.

Com essas características, a definição utilizada para o conceito de emergência de saúde pública se apresenta mais precisa que para o termo doenças emergentes e mais ampla que o conceito de epidemia, na medida em que ambos são restritos à ocorrência do dano, além de que o primeiro conceito se aplica exclusivamente para doenças infecciosas. Cabe destacar que algumas doenças emergentes e epidemias, sempre que representarem risco de disseminação (nacional ou internacional), podem se constituir uma emergência de saúde pública ${ }^{36}$. 
*Orcid (Open Researcher and Contributor ID).
O conceito de emergência de saúde pública vem sendo utilizado rotineiramente pelos países que adotaram o RSI 2005, por meio do monitoramento ativo de eventos de saúde pública (com uso de ferramentas de vigilância ativa e captura eletrônica de rumores); e sua ampla utilização permitiu um aumento na detecção de potenciais emergências desde a implantação do Regulamento.

No Brasil, esse conceito foi adaptado para detecção, análise e resposta às potenciais emergências de importância nacional, ou seja, que apresentam risco de disseminação ou propagação no território nacional. Em 2011, foi publicado Decreto Presidencial $n^{0} 7.616$, por meio do qual foram definidas três situações que poderiam caracterizar uma emergência de saúde pública: a) epidemiológicas (surtos e epidemias); b) desastres; c) desassistência $^{48}$. Evidencia-se que, exceto na ocorrência de desastres, a definição de emergência de saúde pública se aplicaria somente quando da ocorrência de dano à saúde, ou seja, outras situações de risco não seriam consideradas emergências.

\section{Conclusões}

Como visto, o termo emergência de saúde pública, no contexto nacional e internacional, tem sido utilizado para descrever situações (denominadas de eventos de saúde pública) que constituem ou apresentam risco imediato de produção, disseminação ou agravamento de danos à saúde da população, independentemente da natureza ou origem. Esse termo, quando aplicado, sempre tem implicado a necessidade de adoção de medidas imediatas de saúde pública, envolvendo não somente a atenção, a vigilância em saúde, mas também outras áreas de atuação de acordo com as características do evento. Ou seja, é um conceito dirigido para a prática de saúde pública.

Para esse propósito, requer das autoridades de saúde e de todos os demais atores envolvidos na resposta uma avaliação do contexto e das características de cada evento, o que não é uma tarefa fácil, na medida em que, muitas vezes, essas informações são conhecidas no decorrer da própria emergência.

Alguns processos, mecanismos e instrumentos podem ser ainda fortalecidos para melhorar essa capacidade de resposta, os quais têm relação com a definição do próprio conceito de emergência. A título de exemplo, considerando que será objeto de outras publicações nesta Revista: a) desenvolvimento de metodologias para gradação de eventos que podem se constituir emergências de saúde pública, incluindo a caracterização de sinais de alerta e estágios pré-emergência; b) elaboração de planos de preparação e resposta que incluam a adoção de critérios para classificação de emergências de saúde pública; c) a realização de exercícios para avaliação da aplicação desses instrumentos.

Essa é uma tarefa urgente a ser desenvolvida pelas autoridades de saúde, comunidade científica e outros atores envolvidos com o tema, devido ao fato de que as condições para a intensificação na ocorrência de emergências de saúde pública têm ampliado cada vez mais. As mudanças climáticas já têm criado condições para que muitos eventos de grande magnitude ocorram com maior frequência, em curto intervalo de tempo, e produzam maiores danos às populações ${ }^{49}$. As perspectivas para que esse processo se intensifique com o aumento da temperatura acima de 1,5 ${ }^{\circ} \mathrm{C}$ a $2{ }^{\circ} \mathrm{C}$ nas próximas décadas já estão dadas, e alguns cenários já estão descritos ${ }^{50}$. Embora esses cenários ainda apresentem algum grau de incerteza, é certo que o impacto na saúde das populações, especialmente as mais vulneráveis, da produção de emergências de saúde pública será incalculável. Diante desse cenário, é nosso dever, desde já, contribuir para que os seus efeitos sejam os menores possíveis.

\section{Colaborador}

Carmo EH (0000-0001-6343-9967)*é responsável pela elaboração do manuscrito. 


\section{Referências}

1. Omram AR. The epidemiological transition: a theory of the epidemiology of population change. MilbankQ. 1971; 49(4):509-583.

2. Frederiksen H. Feedbacks in economic and demographic transition. Science. 1969; 166(3907):837-47.

3. Olshansky SJ, Ault BA. The fourth stage of the epidemiologic transition. The age of delayed degenerative diseases. MilbankQ. 1986; 64(3):355-391.

4. Frenk J, Frejka T, Bobadilla JL, et al. La transition epidemiológica en América Latina. Boletin OSP. 1991; 111(6):485-496.

5. Barreto ML, Carmo EH, Noronha CV, et al. Mudanças dos padrões de morbi-mortalidade: uma revisão crítica das abordagens epidemiológicas. Physis. 1993; 3(1):127-146.

6. McKeown T. The role of medicine: dream, mirage or nemesis? Oxford: Basil Blakwell; 1979.

7. Buss PM, Pellegrini Filho A. A saúde e seus determinantes sociais. Physis. 2007; 17(1):77-93.

8. Teixeira MG, Paixão ES, Costa MCN. Cambios epidemiológicos recientes en América del Sur. In: Carmo EH, Gemal A, Oliveira S, organizadores. Vigilancia en Salud en Suramérica: epidemiológica, sanitaria y ambiental. Rio de Janeiro: ISAGS; 2013. p. 41-55.

9. Feenney JM, Wallack MK. Taking the terror out of terrorism: mortality data after 9/11. Lancet. 2011; 378(9794):851-952.

10. Khan AS. Public health preparedness and response in the USA since 9/11: a national health security imperative. Lancet. 2011; 378(9794):953-56.

11. Lucchini RG, Hashim D, Acquilla S, et al. A comparative assessment of major international disasters: the need for exposure assessment, systematic emergency preparedness, and lifetime health care. BMC
Public Health [internet]. 2017 [acesso em 2019 jan 25]; 17(1):46. Disponível em: https://bmcpublichealth.biomedcentral.com/articles/10.1186/s12889-0163939-3.

12. Jernigan DB, Raghunathan PL, Bell BP, et al. Investigation of Bioterrorism Related Anthrax, United States, 2001: Epidemiologic Findings. Emerg. Infect. Diseases. 2002; 8(10):1019-1028.

13. Guillemin J. American Anthrax: Fear, Crime, and the Investigation of the Nation's Deadliest Bioterror Attack. New York: Times book; 2011.

14. Drosten C, Günther S, Preiser W, et al. Identification of a Novel Coronavirus in Patients with Severe Acute Respiratory Syndrome. N Engl J Med. 2003; 348(20):1967-76.

15. Hung LS. The SARS epidemic in Hong Kong: what lessons have we learned? J R Soc Med. 2003; 96(8):374378.

16. Peiris JSM, Jong MD, Guanet Y. Avian Influenza Virus (H5N1): a Threat to Human Health. Clin Microbiol Rev. 2007; 20(2):243-267.

17. U.S. Government Printing Office. Hurricane Katrina: A Nation still unprepared. Special report of the Committee on homeland security and governmental affair. Washington, DF: U.S. Government Printing Office; 2006. [acesso em 2019 set 28]. Disponível em: https://www.congress.gov/109/crpt/srpt322/CRPT-109srpt322.pdf.

18. Fineberg HV. Pandemic Preparedness and Response - Lessons from the H1N1 Influenza of 2009. N Engl J Med. 2014; (370):1335-42.

19. Domínguez-Cherit G, Lapinsky SE, Macias AE, et al. Critically Ill Patients With 2009 Influenza A(H1N1) in Mexico. JAMA. 2009; (302):1880-7.

20. Oliveira WK, Carmo EH, Penna GO, et al. Pandemic 
H1N1 influenza in Brazil: Analysis of the first 34,506 notified cases of influenza- like illness with severe acute respiratory infection (SARI). Euro Surveill. 2009; 14(43):pii19362.

21. Brasil. Ministério da Saúde. Informe técnico de Influenza [internet]. 2012. [acesso em 2019 set 28]. Disponível em: http://portalsaude.saude.gov.br/images/ pdf/2014/maio/22/informe- influenza- 2009-20102011- 220514.pdf.

22. Hippel FN. The radiological and psychological consequences of the Fukushima Daiichi accident. Bullet. Atomic Scient. 2011; 67(5):27-36.

23. World Health Organization. Origins of the 2014 Ebola epidemic. One year into the Ebola epidemic [internet]. 2015. [acesso em 2019 set 28]. Disponível em: https://www.who.int/csr/disease/ebola/one-year-report/virus-origin/en/.

24. World Health Organization. Situation report. Ebola virus disease [internet]. 2016. [acesso em 2019 set 28]. Disponível em: http://apps.who.int/iris/bitstream/10665/208883/1/ebolasitrep_10Jun2016_eng. pdf?ua=1.

25. Cenciarelli O, Pietropaoli S, Malizia A, et al. Ebola Virus Disease 2013-2014 Outbreak in West Africa: An Analysis of the Epidemic Spread and Response. Inter. J. Microbiol [internet]. 2015 [acesso em 2019 set 28]; (2015):1-12. Disponível em: https://doi. org/10.1155/2015/769121.

26. Brito CAA, Teixeira MG. Increased number of deaths during a chikungunya epidemic in Pernambuco, Brazil. Mem. Inst. Oswaldo Cruz. 2017; 112(9):650-651.

27. Oliveira WK, França GVA, Carmo EH, et al. Infection- related microcephaly after the 2015 and 2016 Zika virus outbreaks in Brazil: a surveillance- based analysis. Lancet. 2017; 390(10097):861-870.

28. World Health Organization. Emergencies: the history of Zika virus, 2016 [internet]. [acesso em 2019 set 28]. Disponível em: https://www.who.int/emergencies/zika-virus/timeline/en/.
29. Brasil. Ministério da Saúde. Vigilância em saúde no Brasil 2003|2019: da criação da Secretaria de Vigilância em Saúde aos dias atuais. Bol Epidemiol [internet]. 2019 [acesso em 2019 set 28]; 50(esp):1-154. Disponível em: http://www.rets.epsjv.fiocruz.br/biblioteca/vigilancia-em-saude-no-brasil-20032019-da-criacao-da-secretaria-de-vigilancia-em-saude.

30. World Health Organization. Zika epidemiology update [internet]. 2019. [acesso em 2019 set 28]. Disponível em: https://www.who.int/emergencies/diseases/ zika/epidemiology-update/en/.

31. Teixeira MG, Costa MCN, Paixão ES, et al. Conquistas do SUS no enfrentamento das doenças transmissíveis. Ciênc. Saúde Colet. 2018; 23(6):1819-1828.

32. World Health Organization. Ebola virus disease Democratic Republic of the Congo. Disease outbreak news: Update [internet]. 2019 [acesso em 2019 set 28]. Disponível em: https://www.who.int/csr/don/14-november-2019-ebola-drc/en/.

33. Brasil. Ministério da Saúde. Secretaria de Vigilância em Saúde. Boletim Epidemiológico [internet]. 2019. [acesso em 2019 set 28]. Disponível em: https://portalarquivos2.saude.gov.br/images/pdf/2019/setembro/25/boletim-especial-21agol9-web.pdf?fbclid= IwAR3qTQYyo5tG7dYLNXWfj4ymtmIAoJtlolbTn wToAPConwrDnoVpvokyzvo.

34. Centers for Disease Control and Prevention. Measles Cases and Outbreaks [internet]. 2019. [acesso em 2019 set 28]. Disponível em: https://www.cdc.gov/ measles/cases- outbreaks.html.

35. Freitas CM, Barcellos C, Fróes ACIR, et al. Da Samarco em Mariana à Vale em Brumadinho: desastres em barragens de mineração e Saúde Coletiva. Cad. Saúde Pública. 2019; 35(5):1-7.

36. Carmo EH, Oliveira WK, Penna G. Emergências de saúde pública: conceito, caracterização, preparação e resposta. Est. avançados. 2008; 22(64):19-31.

37. Institute of Medicine. Emerging infections: microbial threats to health in the United States. Washing- 
ton, DC: National Academy Press; 1992.

38. Centers for Disease Control and Prevention. Addressing emerging infectious disease threats: a prevention strategy for the United States. Georgia: US Department of Health and Human Services; Public Health Services; 1994.

39. Barreto ML, Teixeira MG, Carmo EH. Infectious diseases epidemiology. J. Epidemiol. Community Health 2006; 60:192-195

40. Institute of Medicine. Microbial threats to health: emergency, detection and response. Washington, DC: National Academy Press; 2003.

41. Waldman EA. Doenças infecciosas emergentes e reemergentes. Revista USP. 2001; (51):128-137.

42. World Health Organization. International Health Regulations (2005). 3. ed. Geneva: WHO; 2016.

43. United States. United States Code. 1982. Titles 4250. Washington, DC: Government Printing Office; 1984. [Supplement I]. [acesso em 2019 set 29]. Disponível em: https://books.google.com.br/boo $\mathrm{ks}$ ? id $=$ fGWbAAAAMAAJ $\& \mathrm{pg}=\mathrm{PA} 5 \& \mathrm{lpg}=\mathrm{PA} 5 \& \mathrm{~d}$ q=July+1,+1944,+ch.+373,+title+III,+\%C2\%A7\%E $2 \% 80 \%$ AF $319 \&$ source $=$ bl\&ots=SKT6_Za6hb\&si $\mathrm{g}=\mathrm{ACfU} 3 \mathrm{U} 3 \mathrm{wnhVaSysZpPqxRRkpqCEAIQJsw}$ Q\&hl=pt- BR\&sa=X\&ved=2ahUKEwj8sfHwhO_ kAhVxG7kGHePEB1EQ6AEwAHoECAgQAQ\# $\mathrm{v}=$ onepage $\& \mathrm{q}=\mathrm{July} \% 201 \% 2 \mathrm{C} \% 201944 \% 2 \mathrm{C} \% 20$ ch. \%20373\%2 C \% 20title \% 2 O I I \% 2 C \% 20 \% $2 \%$ A7\%E2\%80\%AF319\&f=false.

44. Haffajee R, Parmet WE, Mello MM, et al. What Is a Public Health “Emergency”? N Engl J Med. 2014; (371):986-988

45. Salinsky E. Public Health Emergency Preparedness: Fundamentals of the "System" [internet]. 2002. [aces- so em 2019 set 29]. Disponível em: https://www.semanticscholar.org/paper/Public- Health- Emergency- Preparedness\%3A- Fundamentals- Salinsky/ a0ac99f3530b6a8fe43546b267b7d1dbe130400c.

46. Center for Law and Public Health's; Georgetown and Johns Hopkins Universities. The Model State Emergency Health Powers Act: as of October 23, 2001 [internet]. Atlanta: Centers for Disease Control and Prevention; 2001. [acesso em 2019 set 29]. Disponível em: https://biotech.law.lsu.edu/blaw/bt/MSEHPA.pdf.

47. World Health Organization. WHO guidance for the use of Annex 2 of the International Health Regulations (2005) [internet]. 2010. [acesso em 2019 set 28]. Disponível em: https://www.who.int/ihr/publications/annex_2_guidance/en/.

48. Brasil. Decreto $\mathrm{n}^{0} 7.616$, de 17 de Novembro de 2011 [internet]. Dispõe sobre a declaração de Emergência em Saúde Pública de Importância Nacional - ESPIN e institui a Força Nacional do Sistema Único de Saúde - FN- SUS. Diário Oficial da União. 18 Nov 2011. [acesso em 2019 set 29]. Disponível em: http://www. planalto.gov.br/ccivil_03/_Ato2011- 2014/2011/Decreto/D7616.htm.

49. Solomon CG, La Rocque RC. Climate Change - A Health Emergency. N Engl J Med. 2019; (380):209211.

50. Intergovernmental Panel on Climate Change. Especial report. Global Warming of $1.5^{\circ} \mathrm{C}$ [internet]. 2018. [acesso em 2019 set 28]. Disponível em: https://www. ipcc.ch/sr15/.

Recebido em 29/09/2019

Aprovado em 06/05/2020

Conflito de interesses: inexistente

Suporte financeiro: não houve 